\title{
Human activities disturb lake-sediment records of past flood frequencies
}

William Rapuc, P. Sabatier and F. Arnaud

\begin{abstract}
Human activities impact erosion and transport processes in catchments, hence disturbing paleoclimate recording. A thorough study of erosion patterns is therefore necessary to disentangle climate and human forcing when interpreting
\end{abstract} lake sediment-based flood chronicles.

\section{Flood frequencies as a proxy of past extreme precipitation events}

In the current context of global climate change, predicting the evolution of precipitation is particularly challenging: an increase of extreme events is expected globally due to the capacity of a warmer atmosphere to hold more water, although regional trends may differ (IPCC 2012). Assessing this requires the acquisition of long-term hydrological datasets (Wilhelm et al. 2019). As flood occurrence and magnitude are linked to precipitation-regime fluctuation through time, the establishment of regional flood chronicles from natural archives could be a key to evaluate the evolution of precipitation regimes on emerged land (Wilhelm et al. 2017).

Of all the natural archives that lend themselves to such reconstructions, lakes are a prime candidate, as they are widely spread across all continents and act as natural sinks, continuously trapping erosion products from an entire catchment over a long period (Wilhelm et al. 2018). Indeed, during flood events, water-transported detrital particles are deposited on the lake bottom in the form of graded layers that differ from the in-lake continuous sedimentation. The identification of these events, by naked-eye observation or using new methodologies (Rapuc et al. 2020), allows scientists to establish floodoccurrence chronicles. In some cases, the thickness and/or the maximum grain size of deposits can be used to assess the intensity of flood events and even decipher past current-flow velocities (Arnaud et al. 2016; Evin et al. 2019). Numerous studies have thus used flood frequency and intensities based on lake sediments to reconstruct hydrological variations through time (Czymzik et al. 2013; Glur et al. 2013; Wilhelm et al. 2018). However, within a given lake system, the amount and physical characteristics of river-borne sediment not only depend on precipitation patterns, but also on the sediment availability, which is a function of soil erodibility and transport processes.

\section{Impact of human activities on} erosion and transport processes

Sediment availability and transport processes are forced by both climatic fluctuations and human activities. Consequently, provided that the climatic conditions and methodologies of reconstruction are the same, discrepancies between flood chronicles in the same region should provide evidence of the influence of human activities. The Italian Southern Alps offer an ideal playground for such an experiment. Several lakes in this region have been studied and

Age cal kyr BP

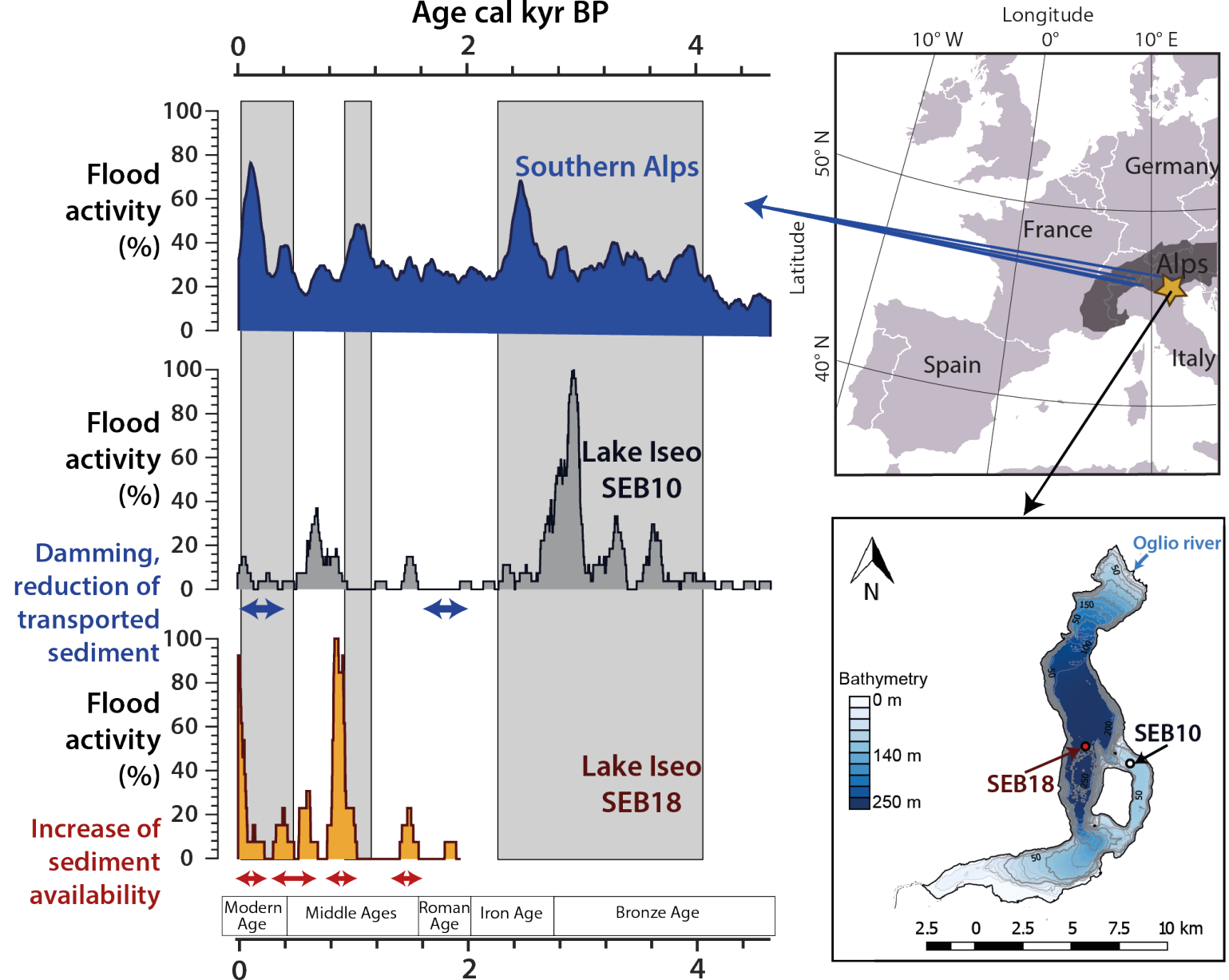

Age cal kyr BP

Figure 1: Flood activities modified from the Southern Alps synthesis of Wirth et al. (2013), the SEB10 (Rapuc et al. 2019) and SEB18 (unpublished) sediment sequences from Lake Iseo. Activity is calculated as a ratio of the instantaneous frequency and the maximum frequency measured in the sequence. Gray shading highlights periods of high regional flood frequency. 


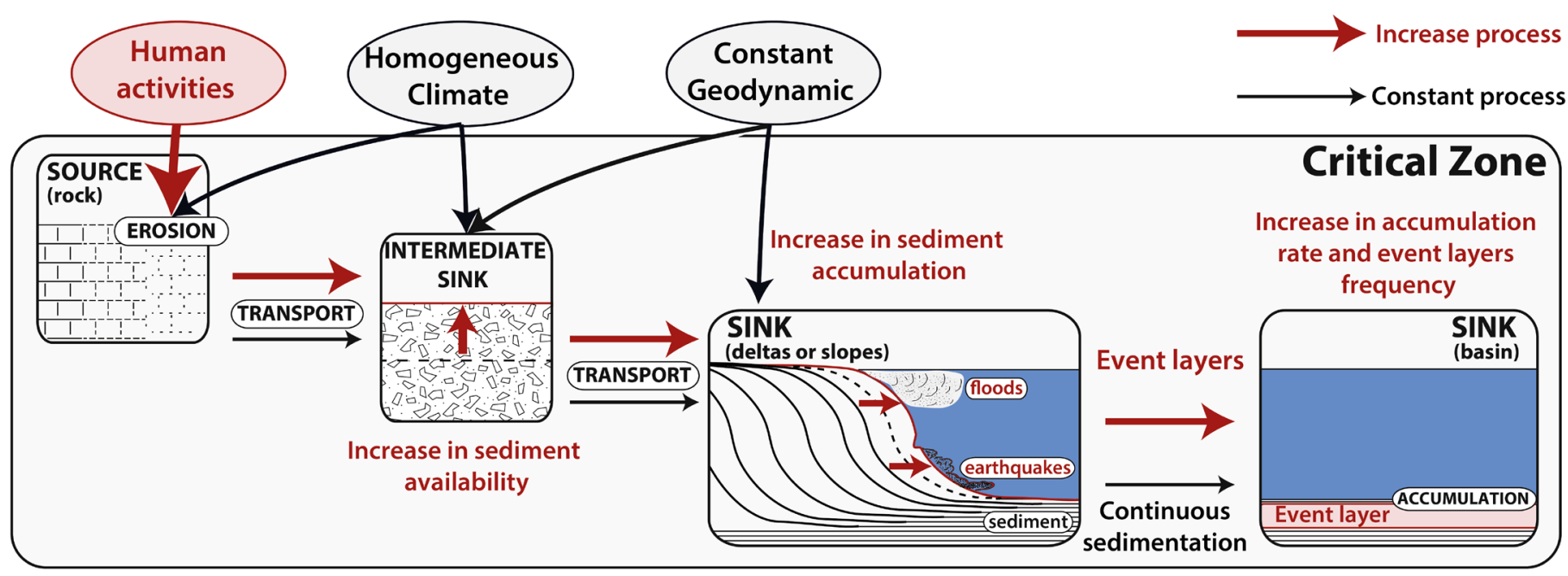

Figure 2: Conceptual model of the Critical Zone erosion cycle in a large catchment and the effects of the three main forcing factors: climate, geodynamics, and human activities.

many flood chronicles have been produced; for example, Wirth et al. (2013) computed a Holocene synthesis of flood frequencies from five lake-sediment sequences from the Southern Alps.

Recently, we produced two flood chronicles from two sediment sequences taken from Lake Iseo, a large perialpine lake. The SEB18 sequence was sampled in the deep basin of the lake, fed by a large catchment $\left(1777 \mathrm{~km}^{2}\right)$. The SEB10 sequence (Rapuc et al. 2019) was retrieved in a shallower basin fed by sediment from a small catchment area $\left(46.5 \mathrm{~km}^{2}\right)$. The SEB10 flood chronicle is consistent with the regional extreme precipitation trend until the Roman Age (approx. 2 cal kyr BP), with an important increase in recorded flood frequency around 4.2 cal kyr BP, reflecting a shift towards wetter climate in Europe (Fig. 1; Wirth et al. 2013). However, the SEB10 sequence differs from the Southern Alps synthesis for periods when human activity is important in the Lake Iseo catchment (Fig. 1). For instance, during the Little Ice Age (LIA, 1300-1860 CE), flood activity in the Southern Alps was high due to a regionally colder and wetter climate, resulting in more frequent precipitation events. However, very few flood layers were deposited in the shallower basin of Lake Iseo at that time. We interpreted that discrepancy as resulting from the anthropization of the main tributaries (streams or rivers flowing into a larger stream or a main stem) through damming, thereby reducing sediment flux to the lake (Rapuc et al. 2019). At that study site, the creation of dams and channels in catchments generally deflected the river flow and trapped sediment upstream, hence reducing the sediment flux to the lake basin and the apparent flood frequency in the lake-sediment record.

A different scenario was documented in SEB18. In this sequence, high flood frequencies are recorded during the Medieval Warm Period (950-1250 CE), and frequencies are lower than expected during the LIA (Fig. 1), in contrast to the regional trend (Wirth et al. 2013; Sabatier et al. 2017). Here, human activity is suspected to have impacted the erosion cycle in the catchment through grazing, agricultural activities, and deforestation, all of which lead to soil destabilization (Fig. 2). When soil erodibility increases and more sediment becomes available, the precipitation intensity necessary to entrain particles from the soil surface decreases (Renard et al. 1991). Hence, even a moderate precipitation event may be recorded as a graded layer in the lake basin, which artificially increases the flood frequency in the sediment record.

The comparison of the SEB10 and SEB18 sequences, taken from different sedimentary basins in the same lake, revealed different lake-sediment responses to the same climate forcing factors (Fig. 1). Moreover, the rise in flood frequency recorded in SEB10 during the High Middle Ages (1000-1250 CE) is delayed by 200 years compared to the SEB18 record. As all other factors are similar at these two core locations, only humantriggered changes in sediment availability or transport processes at the scale of catchment areas can explain these differences.

\section{Summary and future work}

Flood chronicles (frequencies and magnitudes) from lake sediments are robust paleoclimatic proxies in the absence of human activity modifying sediment availability in the catchment. However, when human activity affects the Critical Zone (CZ), defined as the reactive skin of our planet at the interface of lithosphere-atmosphere-hydrosphere-biosphere, by increasing erosion, resulting in increased sediment transport and remobilization, the sensitivity of a lake as a natural archive of the $C Z$ dynamic is disturbed. A human-triggered increase in soil erodibility and sediment availability may therefore result in a decoupling of the recorded flood frequency and the regional climatic conditions. Inversely, stream management can result in a drastic decrease of river-borne sediment input. A similar phenomenon may result from other geodynamical processes, such as earthquakes (Rapuc et al. 2018): the sensitivity of a lake to record seismic shaking increases when sediment accumulation in the delta and on lake slopes increases (Fig. 2). To study paleohydrologic or geodynamic fluctuations, the safest way is then to investigate sediments retrieved from high altitude zones (Sabatier et al. 2017). However, large lakes draining large catchment areas offer us the opportunity to observe large-scale precipitation patterns. They are thus valuable resources for reconstructions of past flood frequency when considered together with the three main forcing factors driving erosion patterns and CZ dynamics throughout the Holocene: climate, geodynamics, and human activities (Fig. 2).

\section{AFFILIATION}

Université Savoie Mont Blanc, Centre National de la Recherche Scientifique, Laboratoire Environnement, Dynamiques et Territoires de la Montagne, Le Bourget du lac, France

\section{CONTACT}

William Rapuc: william.rapuc@univ-smb.fr

\section{REFERENCES}

Arnaud F et al. (2016) Quat Sci Rev 152: 1-18

Czymzik M et al. (2013) Quat Sci Rev 61: 96-110

Evin G et al. (2019) Glob Planet Change 172: 114-123 Glur L et al. (2013) Sci Rep 3: 2770

IPCC (2012) Managing the Risks of Extreme Events and

Disasters to Advance Climate Change Adaptation. Cambridge University Press, 582 pp

Rapuc W et al. (2018) Sedimentology 65: 1777-1799 Rapuc W et al. (2019) Glob Planet Change 175: 160-172 Rapuc W et al. (2020) Sediment Geol 409: 105776 Renard KG et al. (1991) J Soil Water Conserv 46: 30-33 Sabatier P et al. (2017) Quat Sci Rev 170: 121-135

Wilhelm B et al. (2017) For an improvement of our flood knowledge through paleodata. PAGES Floods

Working Group [White Paper], 15 pp

Wilhelm B et al. (2018) Water Secur 3: 1-8

Wilhelm B et al. (2019) WIREs Water 6: e1318

Wirth SB et al. (2013) Quat Sci Rev 80: 112-128 